\title{
Getting on the Bandwagon of Innovative Point-of-Care Diagnostic Devices to Boost Primary Healthcare in India: A Short Critique and Way Forward
}

\author{
Arvind Vashishta Rinkoo*, Anand Kumar Panjiyar, Arnika Sharma, Dinesh Songara, Rajesh Ranjan Singh, \\ Dipanjan Sujit Roy, Rakesh Kumar Srivastava
}

The Wadhwani Initiative for Sustainable Healthcare (WISH), New Delhi, India

\begin{abstract}
This short critique aims to share the evolving regulatory environment and compliance challenges that innovators, nanotechnologists, and public health enthusiasts in India ought to keep in mind before hopping on the bandwagon of innovative point-of-care diagnostic devices in the primary healthcare space. More significantly, the priority-setting approach suggested by the authors needs to be adapted through iterative practice and refinement in order to identify innovative point-of-care diagnostic devices that can eventually raise the quality and cost-effectiveness of healthcare provisions at the last-mile.
\end{abstract}

Keywords: Innovation; Primary healthcare; Point-of-care; Medical devices; India

\section{BACKGROUND}

In October 2018, 197 countries around the world ratified the Declaration of Astana. The Astana declaration reminded the developing countries of the significance of robust primary healthcare as a strong foundation of any health system and as the cornerstone for attaining universal health coverage. If healthrelated sustainable development goals (SDG) are to be achieved, developing countries such as India need to ensure quality primary healthcare for all [1].

SDG 3 calls for health and well-being across all age groups by addressing priority areas such as maternal and child mortality, communicable diseases, non-communicable diseases and mental health, and healthcare workforce. The policy makers worldwide are of considered opinion that without a major shift in the contemporary primary healthcare delivery approach, the base of the pyramid population in developing countries would be left behind in progression towards SDG 3 [2]. To achieve universal health coverage through comprehensive primary healthcare, the potential role of healthcare innovations, especially in resourceconstrained environments, has been extensively explored [3].

In developing countries worldwide, there exists a pressing need to address maternal and child healthcare gaps, along with an ever-growing burden of noncommunicable diseases. The existing health disparities-unabated increase in burden of disease among the lowest socioeconomic strata in the poorest countries-are astronomical. New technology holds tremendous potential to mitigate these disparities. In particular, the recent developments in nanotechnology, mobile technology, and information technology may create an enabling environment to foster affordable pointof-care diagnostics for the last-mile populations [4]. The ability of medical technology innovators to successfully deliver new and affordable products in the areas of maximum primary healthcare needs could go a long way in realizing the aim of universal health coverage in countries such as India.

While innovative point-of-care diagnostic devices hold great promise to improve quality of and access to primary healthcare delivery in India, it is imperative to prudently select innovations that have realistic scale-up potential to eventually create a substantial population-level impact. Besides, the unclear regulatory environment with numerous grey areas concerning introduction and commercialization of new innovative point-of-care diagnostic medical devices confounds the situation. This short critique aims to share the evolving regulatory environment and compliance challenges that innovator, nanotechnologists, and public health enthusiasts in India ought to keep in mind before hopping on the bandwagon of innovative point-of-care diagnostic devices in the primary healthcare space. More significantly, the authors, recognizing the public health priorities and the extant regulatory landscape in India, propose a broad approach to inform various stakeholders in the innovation ecosystem on how to identify high-potential innovative point-of-care diagnostic devices whose

Correspondence to: Arvind Vashishta Rinkoo, The Wadhwani Initiative for Sustainable Healthcare (WISH), New Delhi, India, Tel: +919540318991; E-mail: arinkoo@wishfoundationindia.org

Received: May 10, 2019; Accepted: May 23, 2019; Published: May 31, 2019

Citation: Rinkoo AV, Panjiyar AK, Sharma A, Songara D, Singh RR, Roy DS, et al. (2019) Getting on the Bandwagon of Innovative Point-ofCare Diagnostic Devices to Boost Primary Healthcare in India: A Short Critique and Way Forward. Health Care Current Reviews 7: 243. doi: $10.35248 / 2375-4273 \cdot 19.7 .243$.

Copyright: (C) 2019 Rinkoo AV, et al. This is an open-access article distributed under the terms of the Creative Commons Attribution License, which permits unrestricted use, distribution, and reproduction in any medium, provided the original author and source are credited. 
lab-based success could be translated into effective and efficient population-level public health interventions.

\section{THE CURRENT SCENARIO}

Point-of-care diagnostic devices are defined as small portable devices capable of detecting the presence or absence of a diseasecausing agent, a disease, or quantifying the severity or a change in severity of a disease. Also included in the definition are stand-alone, one-time use devices that require no additional instrumentation, minimally-instrumented devices, and devices that include portable and easy-to-use instrumentation [5].

To address the increasing complexities in the Indian medical device industry, to enable Indian medical device manufacturers to enhance the quality of their products and processes, and to boost the industry's confidence to try out innovative devices, Indian certification of medical devices (ICMED), country's first indigenously developed international class certification scheme and quality assurance system for medical devices manufactured in India, was launched in March 2016 [6]. The ICMED scheme is an initiative of the Association of Indian Medical Device Industry (AIMED) in collaboration with the Quality Council of India (QCI) and the National Accreditation Board for Certification Bodies (NABCB). The scheme has been launched with two levels of certification: ICMED 9000 certification, which is ISO 9001 plus additional requirements, and ICMED 13485, which is ISO 13485 plus additional requirements. The scheme is expected to improve quality, enhance patient safety, and eliminate trading of substandard medical devices in the country. Though the scheme is voluntary, AIMED is strongly advocating to make it mandatory as ICMED certification would be able to fill big regulatory vacuum in quality certification space for medical devices in India.

In 2017, Central Drugs Standard Control Organization (CDSCO) introduced the Medical Device Rules. The Rules distinguish medical devices from pharmaceutical products for the purpose of regulation. Prior to these Rules, notified medical devices in India were regulated as drugs (pharmaceutical products) under the Drugs and Cosmetics Act 1940. Unfortunately, since this Act, in which the definition of 'drug' includes all the medical devices, remains unamended, the Rules under this Act will continue to apply to all medical devices. However, to avoid confusion, the 2017 Rules do clarify that in case of any contradiction between the provisions of 2017 Rules and the Drugs and Cosmetics Rules 1945, the provisions of the 2017 Rules will have effect [7].

In consonance with the Global Harmonization Task Force (GHTF) guidelines, the 2017 Rules introduce a risk-based classification system for regulation of medical devices in India. The classification would be: low (Class A), low moderate (Class B), moderate high (Class C), and high risk (Class D). It is important to note that unlike other countries which give liberty to manufacturers/ importers to classify their product for the purpose of registration, the 2017 Rules do not provide this liberty and the manufacturers/ importers in India will have to follow the classification decided by the Drug Controller General of India (DCGI). Broad parameters for classification of medical devices and in vitro diagnostic medical devices have been laid down in the first schedule of the Medical Device Rules 2017 [8]. In addition, inspections by notified bodies [Quality Management System (QMS) assessments] have been introduced. The new Rules make it compulsory to obtain manufacturing and import licenses for all medical devices. Regarding application for grant of license to the manufacturer, Class A medical devices do not require prior audit by third party or official inspection, Class B medical devices require prior audit by third party but do not require official inspection, and Class C or Class D medical devices require prior official inspection. The application for manufacturer of Class A or Class B medical device will be assessed by the state licensing authority whereas the application for manufacturer of Class $\mathrm{C}$ or Class D medical device will be assessed by the central licensing authority. The application for license to import Class A or Class B medical devices from unregulated jurisdictions can be granted on the strength of a free sale certificate and of either published safety and performance data or clinical investigation in the country of origin. However, an application for import of Class C or Class D medical devices from unregulated jurisdictions can be granted only after their safety and effectiveness have been established through clinical investigation in India. Unregulated jurisdictions are countries other than Australia, Canada, Japan, European Union countries, or the United States of America [7].

The 2017 Rules introduce a new regulatory framework for clinical investigation of medical devices. The Rules have changed the clinical trial scenario for an investigational medical device from a four-phase trial like those for drugs to a two-phase trial. The two phases will be divided into pilot clinical investigation (exploratory study) and pivotal clinical investigation (confirmatory study). Some of the other interesting provisions of this framework are:

a. A fixed timeline of ninety days has been prescribed for the licensing authority to arrive at a decision on application for permission to conduct clinical trial;

b. After obtaining permission to conduct clinical trial, the first subject is required to be enrolled within one year;

c. New concept of "substantial equivalence" to predicate devices has been introduced with respect to approval of medical devices other than investigational medical devices;

$\mathrm{d}$. The clinical performance evaluation of in vitro diagnostic devices is now part of the regulatory framework;

e. Post-marketing surveillance (PMS) is compulsory after gaining marketing approval for the device;

f. Any institute, organization, or hospital run or funded by the Central Government or the State Government is exempted from payment of fees for conduct of clinical investigation; and

g. Academic clinical trials do not require prior approval of the licensing authority for its initiation if the data generated during the study will not be used for obtaining manufacturing or import license.

Form MD22 pertains to grant of permission to conduct clinical investigation of an investigational medical device and form MD24 concerns grant of permission to conduct clinical performance evaluation of new in-vitro diagnostic medical device [8]. Besides, all the processes followed during clinical investigation of any medical device ought to comply with the New Drugs and Clinical Trials Rules 2019 [9].

Use of technology readiness level (TRL), originally applied to space programs, to estimate technology maturation in realms outside its original context, including in case of innovative diagnostic 


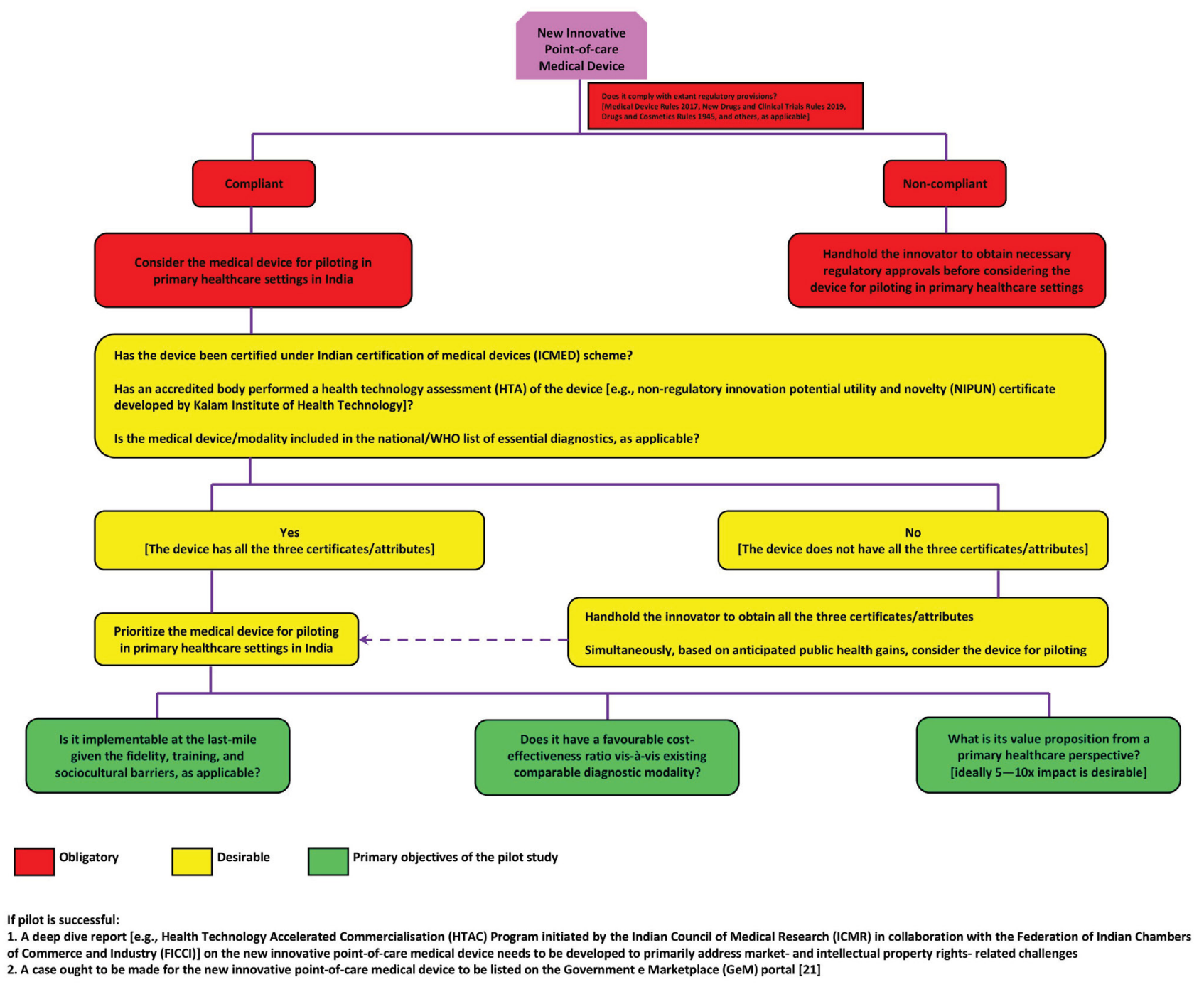

Figure 1: Showing a broad approach to prioritize innovative point-of-care diagnostic devices for piloting in primary healthcare settings in India.

medical devices, has been extensively criticized [10]. In this light, introduction of ICMED certification and Medical Device Rules 2017 is a welcome initiative. Additional resources to inform different stakeholders in the medical device innovation space in India include non-regulatory innovation potential utility and novelty (NIPUN) certificate developed by Kalam Institute of Health Technology, proposed medical technology assessment board in the Department of Health Research-Government of India, Draft "National Essential Diagnostics" list developed by Indian Council of Medical Research (ICMR), First WHO Model List of Essential In Vitro Diagnostics, WHO technical series on health technology assessment of medical devices, WHO recommendations on digital interventions for health system strengthening, and Health Technology Accelerated Commercialisation (HTAC) Program initiated by ICMR in collaboration with the Federation of Indian Chambers of Commerce and Industry (FICCI) [11-17].

\section{THE ROAD AHEAD}

The Tanahashi framework provides a time-tested model for understanding health system performance gaps and how they prevent the intended coverage, quality, and affordability of health services. The cascading model illustrates how health systems lose performance because of challenges at successive levels, each dependent on the previous level [18]. Health system challenges such as lack of trained human resources for health, unaffordable costs for patients and huge out-of-pocket expenditures, geographical inaccessibility, low demand for services, delayed provision of care, low adherence to clinical protocols, to name a few, contribute to accumulated losses in health system performance. These inadequacies restrict the ability to address the gaps in availability, accessibility, and affordability, and undermine the potential to achieve universal health coverage. Going by the Tanahashi framework, while the availability and contact coverage seem to have improved in India during recent years, this success has not been converted into substantial public health gains, suggesting bottlenecks at different levels of the health system. Notably, health innovations could bolster efforts to address these challenges and achieve universal health coverage.

The insufficient supply and uneven distribution of qualified health professionals severely thwart efforts to achieve the health-related SDGs in developing countries such as India. Understandably, innovative human resources for health approaches are at the heart of the global effort to strengthen health systems and revitalize primary healthcare [19]. Innovative health financing is another tool that can be leveraged to make quality healthcare affordable for all, and thus to drastically decrease out-of-pocket expenditures on healthcare in developing countries [20].

Likewise, innovative point-of-care diagnostic devices can be game changers in making quality healthcare affordable for and accessible to the base of the pyramid population. However, for 
these innovations to have substantial population-level benefits, it is imperative to identify innovative point-of-care medical devices that show maximum potential to scale-up into full-fledged public health interventions across the country. Based on the extant regulatory landscape in India, as outlined in this critique, and the current public health priorities, the approach proposed in Figure 1 may assist various stakeholders in the innovation ecosystem to prioritize innovative point-of-care diagnostic devices that hold maximum potential to scale to address the healthcare needs of the last-mile populations across the country.

The Indian public health space represents a unique case of a diverse population with constrained budgets and complex health needs. In this context, the priority-setting approach suggested in this critique needs to be adapted through iterative practice and refinement in order to identify innovative point-of-care diagnostic devices that can eventually raise the quality and cost-effectiveness of healthcare provisions at the last-mile. Instead of largely focusing on technological novelty and sophistication, stakeholders ought to factor in different aspects of the regulatory and public health variables to prioritize affordable, reliable, and cost-effective innovative diagnostic devices for pilot studies and possible scaleups. Evidence-informed use of innovative point-of-care diagnostics can help improve overall primary healthcare system performance and put India on the trajectory of achieving universal health coverage.

\section{DISCLAIMER}

The opinions or views expressed in this article are solely those of the authors and do not necessarily express the views or opinions of the organization to which the authors are affiliated.

\section{ACKNOWLEDGEMENT}

This short critique was undertaken as part of the "State Consortium to Accelerate, Leverage, and Economize (SCALE)"' initiative. SCALE initiative, implemented as collaboration between Wadhwani Initiative for Sustainable Healthcare (WISH) and USAID, acts as a facilitating platform between the government, private sector organizations, innovators and social enterprises, and healthcare ecosystem partners in bringing together financial and technical resources in catalyzing integration of promising health innovations into the state public health system in India.

\section{REFERENCES}

1. Hone T, Macinko J, Millett C. Revisiting Alma-Ata: What is the role of primary health care in achieving the Sustainable Development Goals? Lancet. 2018;392(10156):1461-1472.

2. Lehoux P, Silva HP, Sabio RP, Roncarolo F. The unexplored contribution of responsible innovation in health to Sustainable Development Goals. Sustainability. 2018;10(11):1-21.

3. Peterson HB, Haidar J, Fixsen D, Ramaswamy R, Weiner BJ, Leatherman S. Implementing innovations in global women's, children's, and adolescent's health: realizing the potential for implementation science. Obstet Gynecol. 2018;131:423-430.

4. Abbas JJ, Smith B, Poluta M, Velazquez-Berumen A. Improving health-care delivery in low-resource settings with nanotechnology: Challenges in multiple dimensions. Nanobiomedicine. 2017; 4:1-14.

5. Derda R, Gitaka J, Klapperich CM, Mace CR, Kumar AA, Lieberman M, et al. Enabling the Development and Deployment of Next Generation Point-of-Care Diagnostics. PLoS Negl Trop Dis. 2015;9(5):1-16.

6. Mohan A. Indian certification of medical devices scheme (ICMED) launched. Natl Med J India. 2016;29(3):p:185.

7. Nishith Desai. Analysis of Medical Devices Rules. 2017;p:16.

8. https://mohfw.gov.in/sites/default/files/Medical\%20 Device\%20Rules\%2C\%202017.pdf

9. https://cdsco.gov.in/opencms/opencms/system/modules/ CDSCO.WEB/elements/download_file_division.jsp?num_ $\mathrm{id}=\mathrm{NDI} 2 \mathrm{MQ}==$

10. Heder M. From NASA to EU: The evolution of the TRL scale in Public Sector Innovation. J Innovation. 2017;3:p:23.

11. https://kiht.in/wp-content/uploads/2018/05/ IntroductiontoNipunfinal.pdf

12. https://dhr-sk-nic.wixsite.com/mtab

13. https://www.icmr.nic.in/sites/default/files/whats_new/ Draft_NEDL.pdf

14. World Health Organization. First WHO Model List of Essential in Vitro Diagnostics. 2019;p:66.

15. World Health Organization. Health technology assessment of medical devices. 2011;p:39.

16. World Health Organization. WHOguideline: recommendations on digital interventions for health system strengthening. 2019;p:124.

17. http://ficci.in/pressrelease-page.asp?nid=2932

18. World Health Organization. Innov8 approach for reviewing national health programmes to leave no one behind. 2016;p:239.

19. Dussault G, Franceschini MC. Not enough there, too many here: Understanding geographical imbalances in the distribution of the health workforce Hum Resour Health 2006;4:p:12.

20. Salome B, Gargasson JL. The role of innovative afinancing mechanisms for health. 2016;p:7.

21. https://www.india.gov.in/spotlight/government-emarketplace-procurement-made-smart $\#$ tab=tab-1 